\title{
Calibration of a non-invasive cosmic-ray probe for wide area snow water equivalent measurement
}

\author{
Mark J. P. Sigouin ${ }^{1}$ and Bing C. Si ${ }^{1,2}$ \\ ${ }^{1}$ Department of Soil Science, University of Saskatchewan, Saskatchewan, Canada \\ ${ }^{2}$ Key Laboratory of Agricultural Soil and Water Engineering in Arid and Semiarid Areas of Ministry of Education, \\ Northwest A\&F University, Shaanxi province, China \\ Correspondence to: Bing C. Si (bing.si@usask.ca)
}

Received: 20 November 2015 - Published in The Cryosphere Discuss.: 15 January 2016

Revised: 15 April 2016 - Accepted: 8 May 2016 - Published: 1 June 2016

\begin{abstract}
Measuring snow water equivalent (SWE) is important for many hydrological purposes such as modelling and flood forecasting. Measurements of SWE are also crucial for agricultural production in areas where snowmelt runoff dominates spring soil water recharge. Typical methods for measuring SWE include point measurements (snow tubes) and large-scale measurements (remote sensing). We explored the potential of using the cosmic-ray soil moisture probe (CRP) to measure average SWE at a spatial scale between those provided by snow tubes and remote sensing. The CRP measures above-ground moderated neutron intensity within a radius of approximately $300 \mathrm{~m}$. Using snow tubes, surveys were performed over two winters (2013/2014 and 2014/2015) in an area surrounding a CRP in an agricultural field in Saskatoon, Saskatchewan, Canada. The raw moderated neutron intensity counts were corrected for atmospheric pressure, water vapour, and temporal variability of incoming cosmic-ray flux. The mean SWE from manually measured snow surveys was adjusted for differences in soil water storage before snowfall between both winters because the CRP reading appeared to be affected by soil water below the snowpack. The SWE from the snow surveys was negatively correlated with the CRP-measured moderated neutron intensity, giving Pearson correlation coefficients of -0.90 (2013/2014) and -0.87 (2014/2015). A linear regression performed on the manually measured SWE and moderated neutron intensity counts for 2013/2014 yielded an $r^{2}$ of 0.81 . Linear regression lines from the 2013/2014 and 2014/2015 manually measured SWE and moderated neutron counts were similar; thus differences in antecedent soil water storage did not appear to affect the slope of the SWE vs. neutron relationship.
\end{abstract}

The regression equation obtained from 2013/2014 was used to model SWE using the moderated neutron intensity data for 2014/2015. The CRP-estimated SWE for 2014/2015 was similar to that of the snow survey, with an root-mean-square error of $8.8 \mathrm{~mm}$. The CRP-estimated SWE also compared well to estimates made using snow depths at meteorological sites near $(<10 \mathrm{~km})$ the CRP. Overall, the empirical equation presented provides acceptable estimates of average SWE using moderated neutron intensity measurements. Using a CRP to monitor SWE is attractive because it delivers a continuous reading, can be installed in remote locations, requires minimal labour, and provides a landscape-scale measurement footprint.

\section{Introduction}

Landscape-scale snow water equivalent (SWE) measurements are important for applications such as hydrological modelling, flood prediction, water resource management, and agricultural production (Goodison et al., 1987). Particularly in the Canadian Prairies, snowmelt water is a critical resource for domestic/livestock water supplies and soil water reserves for agriculture purposes (Gray and Landine, 1988). Snow is also a key contributor in recharging Canadian Prairie wetlands, which provide important wildlife habitat (Fang and Pomeroy, 2009).

Common techniques for measuring SWE include snow tubes (gravimetric method), snow pillows, and remote sensing (Pomeroy and Gray, 1995). Snow tube sampling is the most common field survey method for determining SWE and, 
although it provides a point measurement, can be used to survey a larger area. However, snow surveys with snow tubes are labour intensive, can be difficult to perform in remote locations, and are prone to over- and underestimation of SWE, depending on snowpack conditions (Goodison, 1978). Snow pillows can provide SWE measurements in remote locations, but they produce merely a point measurement of roughly 3.5 to $11.5 \mathrm{~m}^{2}$ (Goodison et al., 1981). In addition, snow pillows do not accurately measure shallow snowpacks due to snow removal by wind transport and melting (Archer and Stewart, 1995). Remote sensing has the capability of measuring SWE at large scales based on the attenuation of microwave radiation emitted from Earth's surface by overlying dry snow (Dietz et al., 2012). The applicability of remote sensing techniques for SWE monitoring is limited by their coarse measurement resolutions $\left(\sim 625 \mathrm{~km}^{2}\right)$, their inability to accurately measure wet snow, and their shortcomings in measuring forested landscapes.

A measurement scale between that of the point measurements and the large-scale remote sensing can be desirable due to the high variability in SWE that can occur even over small distances (Pomeroy and Gray, 1995). Shook and Gray (1996) found high variability in snow depth and water equivalent when performing snow surveys with samples every $1 \mathrm{~m}$ along transects in shallow snow covers in the Canadian Prairies. Variability of SWE at this small scale was attributed to differences in wind redistribution and transport, along with variations in surface roughness and micro topography. The high variability of SWE at smaller scales can lead to difficulty when trying to estimate average SWE in a field or catchment from a few point measurements. Instead, labour-intensive snow surveys are generally required. At larger scales, spatial variability of SWE is generally a function of the differences in snowfall and accumulation from varying vegetation and topography (Pomeroy and Goodison, 1997).

The cosmic-ray soil moisture probe (CRP) is a relatively new instrument that was primarily developed for measuring average soil water content at the landscape scale (Zreda et al., 2008) but also has the potential to be a useful tool for measuring SWE (Desilets et al., 2010). The CRP measures neutrons in the fast to epithermal range, which are emitted from soil and inversely related to soil water content due to the neutron moderating characteristic of hydrogen $(\mathrm{H})$. The CRP is an appealing soil water content measurement tool for several reasons. Firstly, it has a landscape-scale measurement area with a radius originally thought to be $\sim 300 \mathrm{~m}$ (Desilets and Zreda, 2013) but recently estimated to be $\sim 200 \mathrm{~m}$ (Köhli et al., 2015). Secondly, it measures soil water content passively (non-radioactive) and non-invasively (CRP sits above the soil surface). Thirdly, the CRP can be deployed easily in remote areas. Lastly, it provides a continuous measurement of average soil water content, often with a temporal resolution of $1 \mathrm{~h}$. The CRP measurement is based on the moderation of neutrons by hydrogen in water; therefore it is also capable of measuring neutrons moderated by hydrogen in snow, i.e. frozen water.

The possibility of measuring SWE from the moderation of neutrons by snow has been known since the late 1970s (Kodama et al., 1979), but studies have been limited. Kodama et al. (1979) used a cosmic-ray moderated neutron sensor buried beneath the snow to measure SWE. Although their results showed a promising relationship between moderated neutron counts and SWE, the fact that the moderated neutron measuring tube was installed beneath the snowpack resulted in merely a point measurement. Others have successfully used cosmic-ray probes buried under snowpacks to measure SWE, including a network of buried probes in France and the Pyrenees of Spain (Paquet et al., 2008). Desilets et al. (2010) compared SWE values measured with a CRP installed above ground to that of SWE values measured manually with a snow tube at the Mt Lemmon Cosmic Ray Laboratory, Arizona. However, the CRP was installed within a laboratory, and Desilets et al. (2010) provided limited details of their study and did not include the relationship they utilised for deriving SWE from measured moderated neutron counts. Using a CRP to monitor SWE was also tested at the Marshall Field Site, Colorado, USA (Rasmussen et al., 2012). Again, limited details were given on the methods of the study and the empirical relationship used to predict SWE from moderated neutron intensity. Additionally, Rivera Villarreyes et al. (2011) observed the possibility to measure snow with neutron counts from a CRP (model CRS-1000) but only explored the relationship between neutron counting rates and snow cover instead of SWE.

The purpose of this study was to establish a simple empirical relationship between SWE and moderated neutrons measured above a snowpack using a CRP. Average SWE in an agricultural field was predicted from CRP moderated neutron measurements using a relationship developed in this study between SWE and moderated neutrons. Predicted SWE from CRP measurements was compared to manual snow surveys and snow precipitation data from multiple locations around the study site.

\section{Methods}

\subsection{Site description and site-specific CRP footprint}

This work was performed at an agricultural field $\left(52.1326^{\circ} \mathrm{N}, 106.6168^{\circ} \mathrm{W}\right)$ located near the University of Saskatchewan in Saskatoon, Saskatchewan, Canada. The field covers roughly 46 ha and is approximately rectangular in shape. This study site was primarily chosen because the estimated measurement footprint of the CRP would fall within the boundaries of the field. The topography of the site is relatively flat and, according to past soil surveys, the texture of the site is silt loam. The field is mostly free from trees and vegetation except for a small cluster at its southern 


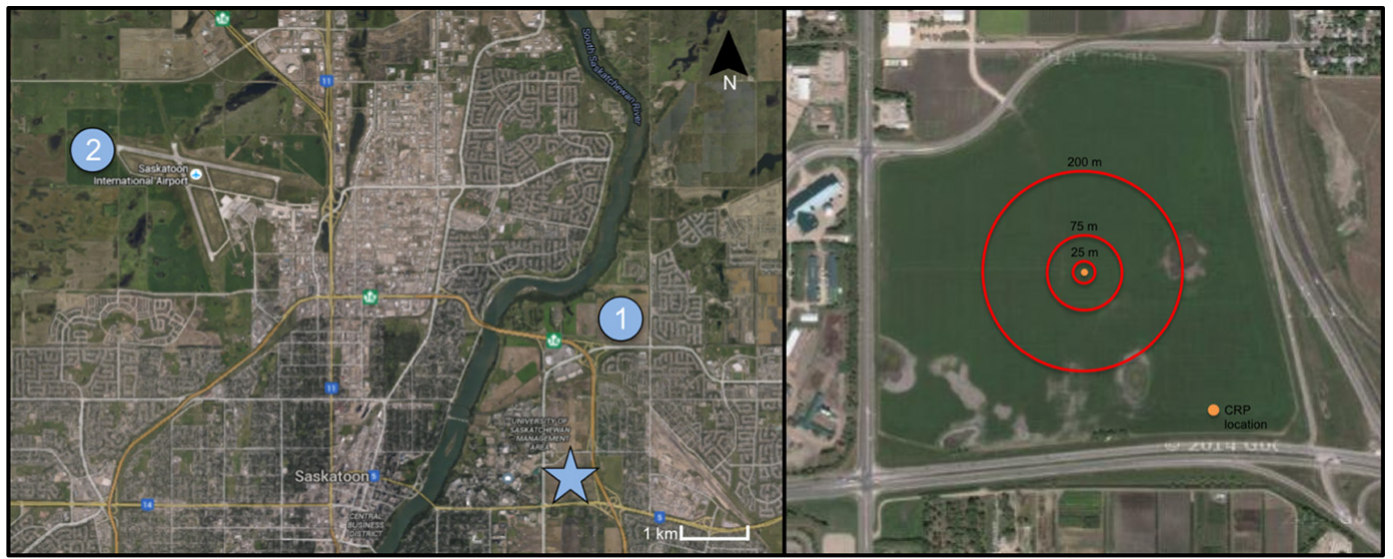

Figure 1. (Left) Location of main study site (star), RCS reference site (1), and Saskatoon Airport RCS reference site (2) in Saskatoon, SK, Canada. (right) Location of the CRP (orange dot) at the agriculture study site and the 25, 75, and $200 \mathrm{~m}$ SWE sampling radials (red lines). Image from Google Maps.

edge and the crop stubble that was left after harvest in autumn of each study year. The same study site was used for both (2013/2014 and 2014/2015) winter field seasons. Wheat stubble (height $\sim 20 \mathrm{~cm}$ ) was present on the field for the 2013/2014 winter, and canola stubble (height $\sim 25 \mathrm{~cm}$ ) for the 2014/2015 winter. Also, a set-move wheeled irrigation line was located across the centre of the field during the 2013/2014 winter, causing increased snow accumulation along the line, but the irrigation line was removed before the 2014/2015 winter.

The altitude and average air pressure of Saskatoon are $482 \mathrm{~m}$ and $955 \mathrm{hPa}$ respectively. According to Desilets and Zreda (2013) the measurement footprint of the CRP changes slightly based on air pressure of the site. Air pressure affects the neutron moderation length, which controls the footprint of the CRP. Using Eq. (21) from Desilets and Zreda (2013) and sea level as a reference (moderation length $=150 \mathrm{~m}$; air pressure $=1013 \mathrm{hPa}$ ), the moderation length for Saskatoon was found to be $159 \mathrm{~m}$. The radius of the CRP footprint is 2 times the moderation length. Therefore, the site-specific CRP footprint for Saskatoon has a radius of $318 \mathrm{~m}$.

\subsection{CRP and background water content}

The model of CRP used in this study was a CRS-1000/B (Hydroinnova, NM, USA). This model consists of two neutron detector tubes and an Iridium modem data logger for remote data access. One of the detector tubes is shielded (or moderated) to measure neutrons of slightly higher energy (epithermal to fast range) and one tube is unshielded to measure lower energy neutrons (slow neutrons). The neutrons detected by the moderated tube in the epithermal to fast range are referred to as moderated neutrons. Slow neutrons are affected by more than just $\mathrm{H}$, including other neutron absorbing elements in soil such as $\mathrm{B}, \mathrm{Cl}$, and $\mathrm{K}$ (Desilets et al., 2010). Also, the relationship between the bare tube count- ing rate and SWE are thought to be less straightforward than the moderated neutron and SWE relationship. Thus, only the moderated neutron count was used in this study following the practice established for soil moisture observations (Zreda et al., 2012). An in-depth description of how the CRP measures neutrons can be found in Zreda et al. (2012). The CRP was installed in the centre of the field site (Fig. 1) from the end of October 2013 until after snowmelt in the spring of 2014 (2013/2014 winter). Similarly, for the 2014/2015 winter, the CRP was installed in the same location and again collected data until snowmelt in spring of 2015. After installation of the CRP and before the first snowfall event of both winters, average soil water content within the CRP measurement footprint was measured manually from soil cores of known volume. The soil sampling scheme was as follows: 18 total sampling locations comprised of 6 locations evenly spaced along 3 radials spanning outward of the CRP $(25,75$, and $200 \mathrm{~m}$ ). Each location was sampled in $5 \mathrm{~cm}$ increments to a depth of $30 \mathrm{~cm}$. This sampling scheme follows the typical method for calibrating CRPs for measuring soil water content (Franz et al., 2012b). Volumetric water content was measured from the cores via the oven-drying method (Gardner, 1986). The average bulk density and total porosity from the $0-30 \mathrm{~cm}$ soil samples were $1.31 \mathrm{~g} \mathrm{~cm}^{-3}$ and $0.51 \mathrm{~cm}^{3} \mathrm{~cm}^{-3}$ respectively. For the top $10 \mathrm{~cm}$, the average bulk density and total porosity were $1.01 \mathrm{~g} \mathrm{~cm}^{-3}$ and $0.61 \mathrm{~cm}^{3} \mathrm{~cm}^{-3}$ respectively. Organic matter and crop residue incorporated into the soil caused the lower bulk density in the top $10 \mathrm{~cm}$ of the soil at the site.

The soil water storage in the top $10 \mathrm{~cm}$ of the soil profile, prior to snowfall, was estimated for both winters from the measured average soil water content and precipitation data. Precipitation data were collected from a Saskatchewan Research Council (SRC) climate station $\left(52.1539^{\circ} \mathrm{N}, 106.6075^{\circ} \mathrm{W}\right)$ located near the study site. Rainfall events recorded after soil sampling but, before the ap- 
pearance of the snowpack, were added to the antecedent soil water storage. It was assumed that all of the water from rain events before snowfall entered the soil and evapotranspiration was negligible due to the low air temperatures. The soil water storage in the top $10 \mathrm{~cm}$ of the soil profile was $2.15 \mathrm{~cm}$ in 2013 and $4.53 \mathrm{~cm}$ in 2014, creating a difference of $2.38 \mathrm{~cm}$ in water storage between the beginnings of the 2013 and 2014 winters.

\subsection{Raw moderated neutron correction}

The raw neutron counts must be corrected for differences in air pressure, atmospheric water vapour, and the temporal variation of incoming cosmic-ray flux. Corrected neutron counts are attained from multiplying the raw counts by correction factors:

$N_{\mathrm{COR}}=N_{\mathrm{RAW}} \cdot F_{\mathrm{p}} \cdot F_{\mathrm{W}} \cdot F_{\mathrm{i}}$,

where $N_{\mathrm{COR}}$ is the corrected moderated neutron count, $N_{\text {RAW }}$ is the raw moderated neutron count, $F_{\mathrm{p}}$ is the air pressure correction factor, $F_{\mathrm{w}}$ is the atmospheric water vapour correction factor, and $F_{\mathrm{i}}$ is the variation of incoming cosmicray flux correction factor.

Correcting for differences in air pressure is important since the incoming cosmic-ray flux is attenuated with increasing nuclei present in the atmosphere, i.e. as air pressure increases (Desilets and Zreda, 2003). $F_{\mathrm{p}}$ is calculated with the following equation:

$F_{\mathrm{p}}=e^{\left(\frac{P-P_{0}}{L}\right)}$

where $e$ is the natural exponential and $P$ is the measured air pressure $(\mathrm{hPa})$ at the site during the moderated neutron count time. Air pressure was measured near the CRP using a WeatherHawk 232 Direct Connect Weather Station (WeatherHawk, UT, USA). $P_{0}$ is a reference air pressure chosen to be $1013 \mathrm{hPa}$ (average sea-level air pressure). $L$ represents the mass attenuation length $(\mathrm{hPa})$, which is a function of latitude and atmospheric depth (Desilets and Zreda, 2003). The mass attenuation length for Saskatoon was found to be $127.5 \mathrm{hPa}$.

Since neutron counts are mainly related to the amount of hydrogen molecules in an area, raw moderated neutron counts must also be corrected for differences in atmospheric water vapour. Rosolem et al. (2013) found the following correction function for atmospheric water vapour:

$F_{\mathrm{w}}=1+0.0054 \cdot\left(p_{v 0}-p_{v 0}^{\mathrm{ref}}\right)$,

where $p_{v 0}$ is the absolute humidity $\left(\mathrm{g} \mathrm{m}^{-3}\right)$ at the site during the measurement time; $p_{v 0}^{\text {ref }}$ is the reference absolute humidity and was set to that of dry air $\left(0 \mathrm{~g} \mathrm{~m}^{-3}\right)$. Relative humidity and air temperature, which are both used to calculate absolute humidity, were measured at the site using the WeatherHawk weather station.

Correcting for the temporal variation of the cosmic-ray flux is the final correction for the raw neutron counts. This correction is performed using counts from neutron monitors along with the following equation:

$F_{\mathrm{i}}=\frac{N_{\mathrm{avg}}}{N_{\mathrm{nm}}}$,

where $N_{\text {avg }}$ is the average neutron monitor count rate during the study period and $N_{\mathrm{nm}}$ is the specific hourly neutron monitor count rate at the time of interest. Data from the neutron monitor at Fort Smith $\left(60.02^{\circ} \mathrm{N}, 111.93^{\circ} \mathrm{W}\right)$, Canada, were used in this study. The Fort Smith data were obtained from the NMDB database (www.nmdb.eu). The corrected moderated neutron counts were then averaged over $13 \mathrm{~h}$. A $13 \mathrm{~h}$ running average was used for the moderated neutron intensity counts in order to reduce the inherent noise of the hourly moderated neutron data and reduce measurement uncertainty, yet still allow responses to precipitation events to be observed (Zreda et al., 2008). For future studies, a CRP with larger detector tubes, such as the CRS-2000/B, should be used to further reduce the neutron intensity noise.

\subsection{Snow surveys}

Snow surveys were performed periodically in the field each winter within the estimated CRP measurement footprint. During the 2013/2014 winter, seven surveys consisting of 18 sampling points were completed. Throughout the 2014/2015 winter, 11 surveys composed of 36 sampling points were performed. The SWE sampling points were evenly spaced along each of the individual soil sampling radials, 25, 75, and $200 \mathrm{~m}$, away from the CRP. This sampling scheme is based on a CRP footprint of $\sim 300 \mathrm{~m}$ radius. According to Köhli et al. (2015), the CRP footprint might be smaller $(\sim 200 \mathrm{~m}$ radius). This study was performed prior to the new estimations of the CRP footprint so a radius of $\sim 300 \mathrm{~m}$ was still assumed and samples along the $200 \mathrm{~m}$ radial were included in the snow surveys. The sampling radials are unevenly spaced away from the CRP to allow for the calculation of a simple arithmetic mean of SWE based on the non-linear decreasing sensitivity of the CRP with increasing distance away from the probe (Zreda et al., 2008). Snow cores were collected for SWE using a Meteorological Service of Canada snow tube with an inner diameter of $7.04 \mathrm{~cm}$. The cores were carefully transferred to plastic bags, sealed, and transported to the lab for processing. The depth of snow was measured in situ at each sampling location during the snow survey.

\subsection{Snow depth data}

Snow depth data from two reference sites were used for a first-order comparison to the snow surveys and CRP data. These were the SRC site and Saskatoon Airport Reference Climate Station (RCS) site $\left(52.1736^{\circ} \mathrm{N}, 106.7189^{\circ} \mathrm{W}\right)$, located approximately 2.4 and $8.2 \mathrm{~km}$ from the CRP. At both reference sites, snow depths were measured using a SR50 Sonic Ranging Sensor (Campbell Scientific, Canada). Man- 
ual readings with measuring sticks were also performed occasionally at the SRC site.

The snow depth data were converted to SWE values in order to compare to the snow surveys and CRP data. Shook and Gray (1994) studied shallow snow covers (less than $60 \mathrm{~cm}$ ) in the province of Saskatchewan over 6 years and found the following linear relationship for predicting SWE from snow depth:

$\mathrm{SWE}=2.39 D+2.05$,

where $D$ is snow depth in centimetres and SWE is in millimetres. Equation (5) was used to estimate SWE using the snow depth data from the two reference sites. Although the SRC and Saskatoon Airport RCS sites are located a few kilometres away from the study site, comparing estimated SWE from these reference sites to SWE estimated from the CRP is still useful when we look only at the overall trend of snow accumulation.

\section{Results and discussion}

\subsection{Snow surveys and moderated neutron intensity}

Moderated neutron intensity recorded by the CRP and SWE from snow surveys are shown in Fig. 2. According to the field snow surveys from both winters (2013/2014 and 2014/2015), the measured mean SWE peaked at $64.7 \mathrm{~mm}$ in 2013/2014 and $53.7 \mathrm{~mm}$ in $2014 / 2015$. The SWE varied significantly throughout the field between individual sampling locations, despite the study site being relatively homogeneous. The standard deviation of SWE for the snow surveys ranged from 5.7 to $18.1 \mathrm{~mm}$ in $2013 / 2014$ and 2.5 to $10.7 \mathrm{~mm}$ in 2014/2015. It should be noted that the final five mean SWE values for 2014/2015 include the addition of a shallow ice layer that was observed along the soil surface, below the entire snowpack. The ice layer formed after a warm period near the end of January 2015 and was present at each SWE sampling location. The ice layer was too dense for the teeth of the snow tube to cut through, and thus the depth of ice was recorded. An average ice layer depth of $1 \mathrm{~cm}$ was observed during the last five snow surveys. The ice water equivalent was calculated from an assumed density of $0.916 \mathrm{~g} \mathrm{~cm}^{-3}$, found by Hobbs (1974) to be the average density of ice. A value of $9.2 \mathrm{~mm}$ was then added to the mean SWE measured during the final five snow surveys of 2014/2015.

Early in both winters (early November), the moderated neutron intensity decreased quite drastically in response to the first snow events of the season. These results are consistent with Desilets et al. (2010) who, although they did not have precipitation data, found that observed snowfall events caused quick decreases in moderated neutron intensity. The first cluster of precipitation events and first significant decrease in moderated neutron intensity in 2014/2015 (Fig. 2) represent rainfall events. The second distinct decrease in
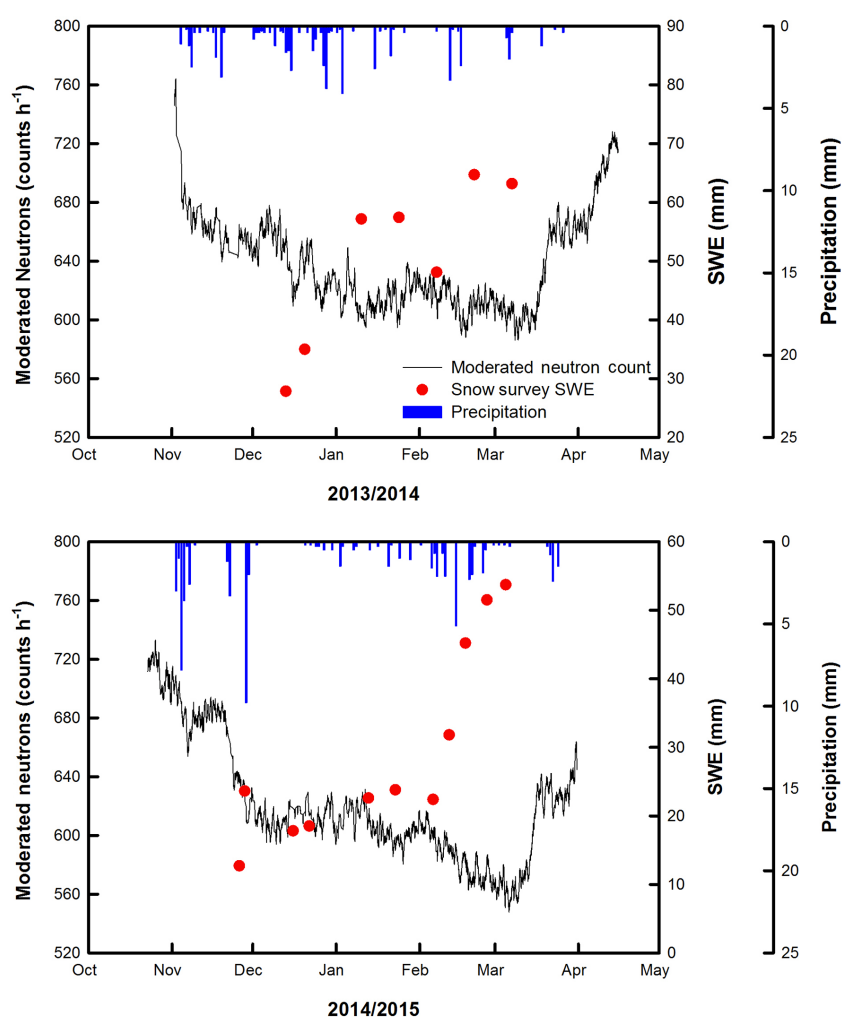

Figure 2. Moderated neutron intensity and snow survey SWE for 2013/2014 (top) and 2014/2015 (bottom). Precipitation sourced from SRC site and represents daily precipitation.

moderated neutron intensity, in late November 2014/2015, was caused by snowfall events. In Fig. 2, all of the precipitation events for 2013/2014 were snowfall events.

In general, moderated neutron intensity shows an expected negative relationship with both precipitation events and SWE, resulting in decreased moderated neutron intensity and increased mean SWE in response to precipitation. A relatively strong negative correlation between mean SWE and the moderated neutron intensity at the time of snow survey can be seen from the Pearson's correlation coefficients -0.90 and -0.87 for $2013 / 2014$ and $2014 / 2015$ respectively. These correlations show there is potential for predicting SWE from moderated neutron intensity measured above the snowpack.

\subsection{Regression of moderated neutron intensity and SWE}

Simple linear regression was performed on the manually measured SWE values and the corresponding moderated neutron intensity during the snow survey. Initial regressions showed that both 2013/2014 and 2014/2015 had similar slopes but quite different intercepts (Fig. 3). The difference in intercepts was attributed to the differences in soil water storage in the upper soil profile prior to snowfall. The previously mentioned calculated difference in soil water storage 


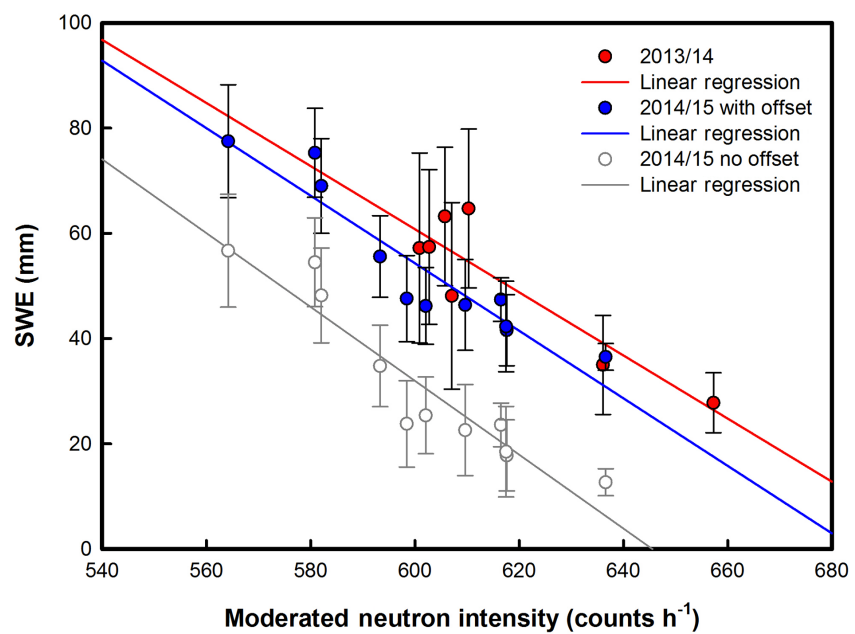

Figure 3. Linear regression of 2013/2014, 2014/2015 with the soil water storage offset (blue), and 2014/2015 with no offset (grey). The red line is the linear regression for $2013 / 2014$. The blue and grey lines represent the linear regressions for the 2014/2015 data with and without the soil water storage offset respectively. Error bars represent standard deviation of SWE.

in the top $10 \mathrm{~cm}$ of the soil profile of $23.8 \mathrm{~mm}$ was added to the SWE values of 2014/2015 and linear regression was repeated. The added soil water storage caused the intercept of the 2014/2015 regression line to match more closely with the intercept for 2013/2014 as can be seen in Fig. 3. This result indicates that the CRP reading is still being affected by water present in the upper soil profile despite the presence of a snowpack. Thus, knowledge of the initial or background soil water storage in the top of the soil profile before each winter is important for predicting SWE from moderated neutron intensity from year to year. However, the combined measurement depth of the CRP in the snowpack and underlying soil is not fully known. With no standing water covering the soil surface, the CRP measurement depth is thought to range from $70 \mathrm{~cm}$ (dry soil) to $12 \mathrm{~cm}$ (saturated soil) (Zreda et al., 2008). In pure water, Franz et al. (2012a) found the effective measurement depth to be $\sim 58 \mathrm{~mm}$ (i.e. the CRP measurement becomes saturated when more than $58 \mathrm{~mm}$ of water is above the soil surface. The effective measurement depth is considered the depth at which $86 \%$ (two e-folds) of the measured neutrons originate assuming an exponential decrease in neutron intensity with depth. However, we observed a CRP response to SWE values of greater than $70 \mathrm{~mm}$, when including antecedent soil water in the upper soil profile, during the 2014/2015 winter. It is not completely clear why distinct CRP responses occurred at SWE values greater than $70 \mathrm{~mm}$.

The individual regression curve for the 2013/2014 data is shown in Fig. 4 with the best-fit linear regression equation for the data producing an $r^{2}$ of 0.81 . Due to the similarity between the regression lines for 2013/2014 and 2014/2015 with

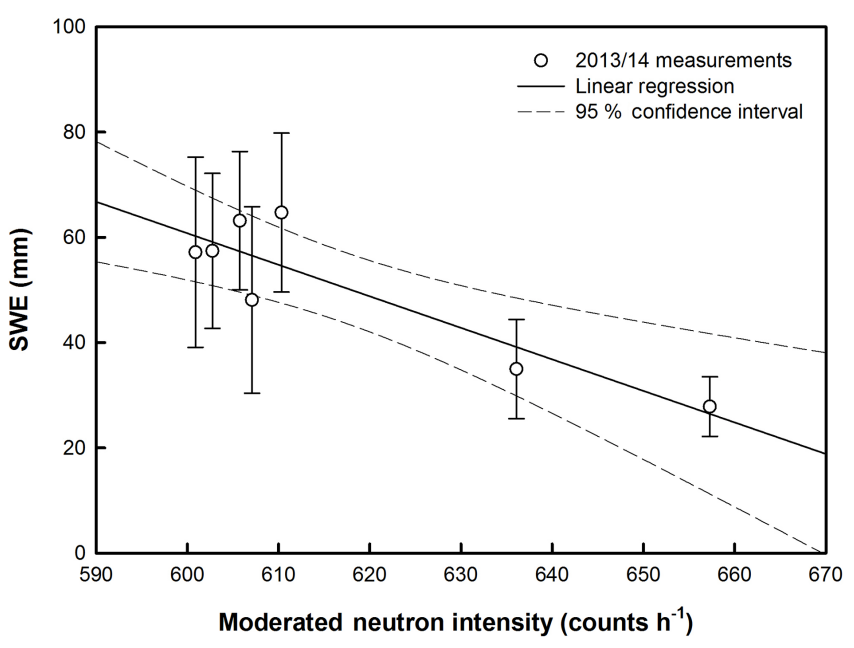

Figure 4. Linear regression of 2013/2014 measured SWE and corresponding moderated neutron intensity. Error bars represent standard deviation of SWE.

the soil water storage offset, the 2013/2014 regression equation was used for estimating SWE in 2014/2015. The similarity between the regression lines indicates that the slope of the model is not affected by differences in soil water storage near the soil surface. The linear regression and relationship of the SWE and moderated neutron intensity data differ from the exponential relationship that Kodama et al. (1979) found and employed for estimating SWE from moderated neutron intensity. An exponential curve was fit to the 2013/2014 and $2014 / 2015$ data, but the $r^{2}$ was not improved drastically compared to the linear regression; thus linear regression was used for modelling SWE from moderated neutrons. The error bars in Figs. 3 and 4, representing standard deviation of manually measured SWE, generally overlap their associated regression line. This indicates that the linear regression captures the variability revealed by the manual snow surveys.

\subsection{Estimating SWE from moderated neutron intensity above snowpack}

The CRP-estimated SWE from moderated neutron intensity measurements for both 2013/2014 and 2014/2015 winters are shown in Fig. 5. The 2013/2014 regression equation was used to estimate SWE based on the moderated neutron intensity in the form of

$\mathrm{SWE}_{\mathrm{CRP}}=-0.6044\left(N_{\mathrm{COR}}\right)+423.46$,

where $\mathrm{SWE}_{\mathrm{CRP}}$ is in $\mathrm{mm}$ and $N_{\mathrm{COR}}$ is the corrected moderated neutron intensity. A correction for the difference in soil water storage between 2013/2014 and 2014/2015 was applied when estimating SWE for 2014/2015 by subtracting $23.8 \mathrm{~mm}$ from the calculated $\mathrm{SWE}_{\mathrm{CRP}}$.

For both winters, the CRP-estimated SWE match the manually measured SWE well. Of course for 2013/2014 
the manually measured SWE corresponds nicely to the CRP-estimated SWE since the regression equation from 2013/2014 was used for SWE prediction. The CRP-estimated SWE for 2014/2015 also agrees with manually measured SWE. The root-mean-square error (RMSE) and mean absolute error for the 2014/2015 CRP-estimated SWE is 8.8 and $7.5 \mathrm{~mm}$ respectively. These error results are comparable to Rasmussen et al. (2012), who found an RMSE of $5.1 \mathrm{~mm}$ between SWE estimated from snow depth and from a CRP. The 2014/2015 CRP-estimated SWE errors are considerably lower compared to other large-scale SWE measurement methods such as remote sensing. Large-scale $(25 \mathrm{~km}$ resolution) remotely sensed SWE measurements using microwave radiation for the GlobSnow project (Luojus et al., 2010; Dietz et al., 2012) had RMSE values ranging from 24 to $77 \mathrm{~mm}$ when compared to snow courses.

Snowpack melt occurred during both winters, brought about by warmer temperatures and consistent solar radiation, with significant melts occurring in February 2014 and January 2015. The CRP-estimated SWE responded to the melt in February 2014 with a noticeable decrease at the end of January and early February (Fig. 5). However, the CRP overestimated SWE during the melt period in January 2015 (Fig. 5). In January 2015 the manually measured SWE was approximately $20 \mathrm{~mm}$, while the CRP-estimated SWE was generally between 30 and $40 \mathrm{~mm}$. In late January 2015 the CRP-estimated SWE did finally decrease with a corresponding decrease in manually measured SWE. This overestimation of SWE by the CRP during snowpack melt periods is likely caused by a significant portion of snowmelt water that is removed from the snowpack and deposited in or above the upper soil profile. Any snowmelt water that infiltrated or remained on the very top portion of the soil profile would affect the moderated neutron intensity, thus causing the CRP to estimate greater amounts of SWE.

Desilets et al. (2010) also witnessed an overestimation of SWE by the CRP following a snowmelt period. Nearly all of the snowpacks they studied appeared to have melted close to the end of their winter study season followed by a large snowfall event causing a rapid increase in CRP-predicted SWE. Manual measurements of SWE around the CRP location gave a mean of roughly $25 \mathrm{~mm}$, while the CRP-estimated SWE was around $55 \mathrm{~mm}$ (Fig. 2 in Desilets et al., 2010). This CRP overestimation of SWE could also be attributed to snowmelt water remaining in the top of the soil profile and decreasing the moderated neutron intensity.

\subsection{Comparison of CRP and snow-depth-estimated SWE}

The CRP-estimated SWE was also compared to estimated SWE from snow depth measurements at two different reference sites near the study site. The linear relationship between SWE and snow depth found by Shook and Gray (1994) was used to estimate SWE from point measurements of snow
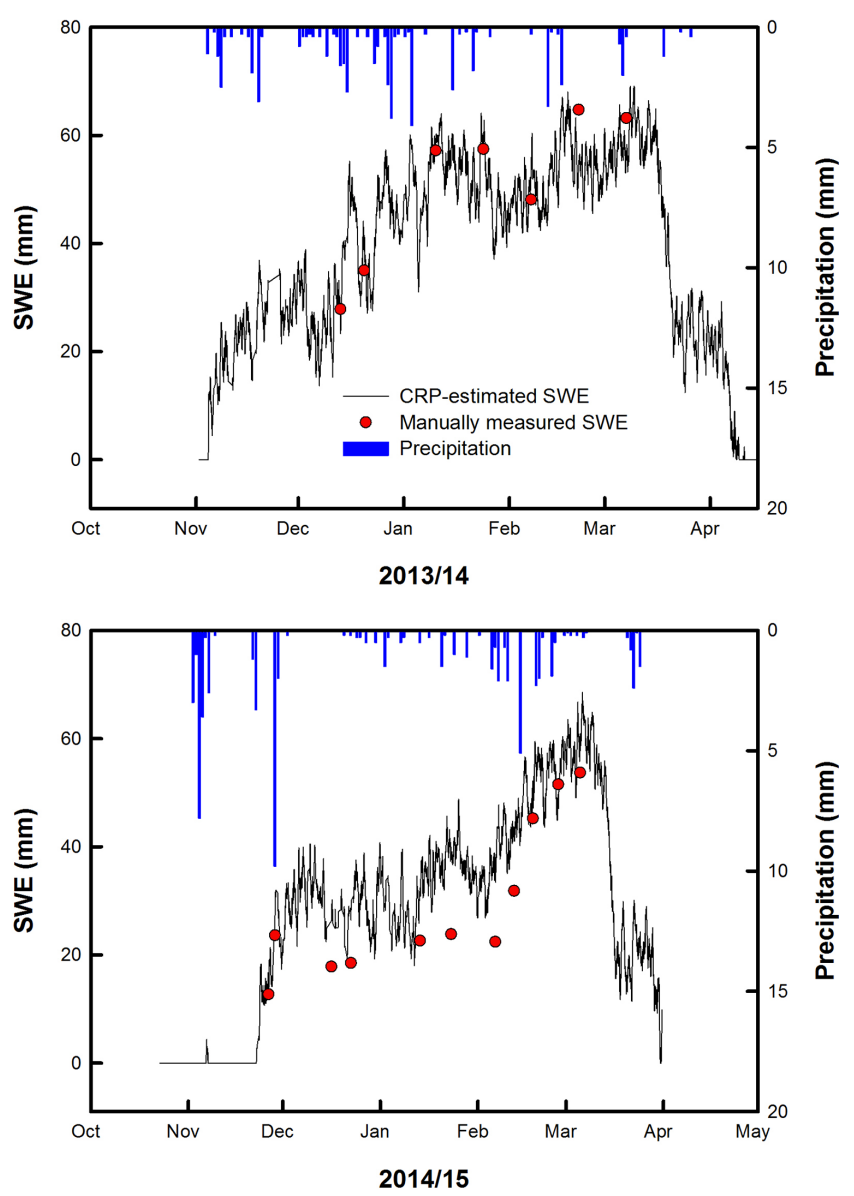

Figure 5. CRP-estimated SWE and manually measured SWE for 2013/2014 (top) and 2014/2015 (bottom).

depth at the reference sites. The average SWE and snow depth from the 2013/2014 and 2014/2015 snow surveys followed the Shook and Gray (1994) relationship quite well (Fig. 6). Figure 7 contains the CRP-estimated SWE along with SWE estimated from the SRC and Saskatoon Airport RCS sites. As mentioned earlier, the SRC site is roughly $2 \mathrm{~km}$ away from the study site and the Saskatoon Airport RCS site is approximately $8 \mathrm{~km}$ away. The reference sites are similar to the study site in the way that all three are open areas containing few to no trees. The SRC site, located in the middle of an agricultural field (located within the city of Saskatoon) and nearest to the study site, is similar to the CRP location in terms of topography and the surrounding area. It is difficult to quantitatively compare the snow depth results to the CRPestimated SWE since the two measurement sites are located some distance from the CRP and only a single point measurement was made at each of these reference sites. Thus, the snow depth measurements might not be accurate or spatially representative for SWE, but they do allow the examination of the snowpack dynamics in this region. 


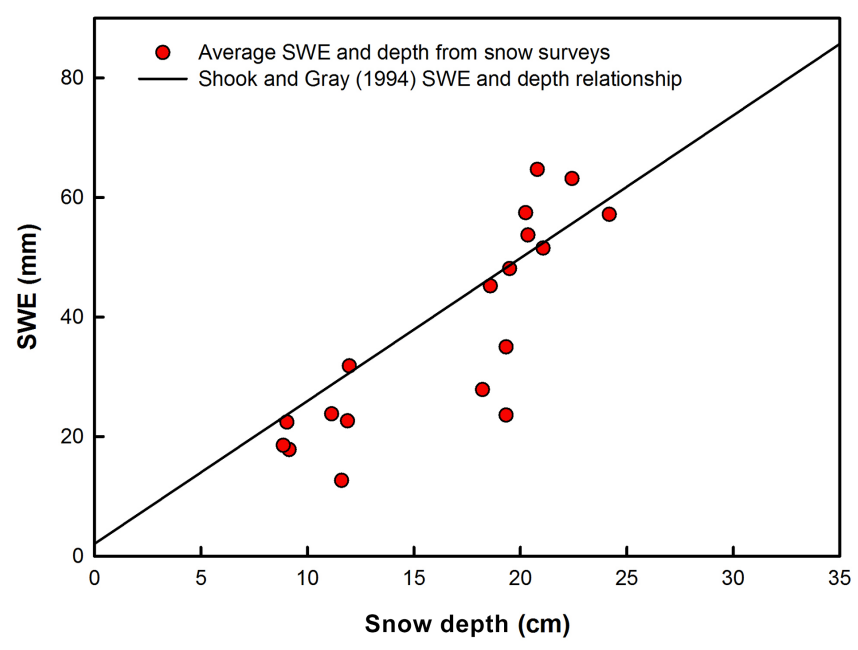

Figure 6. The average SWE and snow depth from the 2013/2014 and 2014/2015 snow surveys at the CRP study site. The black line represents the linear relationship between SWE and snow depth found by Shook and Gray (1994) for shallow $(<60 \mathrm{~cm})$ snowpacks in the Canadian Prairies.

Looking at Fig. 7, it can be seen that SWE dynamics for both winters at the SRC and Saskatoon Airport RCS sites are quite close to the CRP-estimated SWE. At the beginning of each winter SWE appears at very similar times at all three sites. Increases in SWE also appear at comparable times at all sites. The aforementioned melt periods in January and February of each winter appear more noticeable in the SRC and Saskatoon Airport RCS estimates than in the CRP estimates. In February 2014 it can be seen that the SRC-estimated SWE is consistently lower than the CRP-estimated SWE. Higher SWE at the study site could be attributed to increased accumulation of snow along the irrigation line in the centre of the CRP study site.

It is also interesting to note the late accumulation of snow near the end of March 2015. All three sites show an increase in SWE from the final snowfall event at the end of the winter in 2015. Despite all three sites being over $2 \mathrm{~km}$ away from each other and the strong spatial variability of SWE, the general trend is comparable signifying that the CRP is performing well in terms of estimating SWE.

\subsection{Footprint for CRP-estimated SWE}

In this study, the footprint of the CRP was assumed to be $\sim 300 \mathrm{~m}$ based on original studies using the CRP for soil water content measurements (Desilets and Zreda, 2013). Recent evidence displays that the CRP footprint might range from 130 to $240 \mathrm{~m}$ depending on soil water content and that a horizontal weighting function is needed to compare CRP measurements to other point measurements (Köhli et al., 2015). With an assumed footprint of $\sim 300 \mathrm{~m}$, snow samples along 25,75 , and $200 \mathrm{~m}$ radials around the CRP were included in
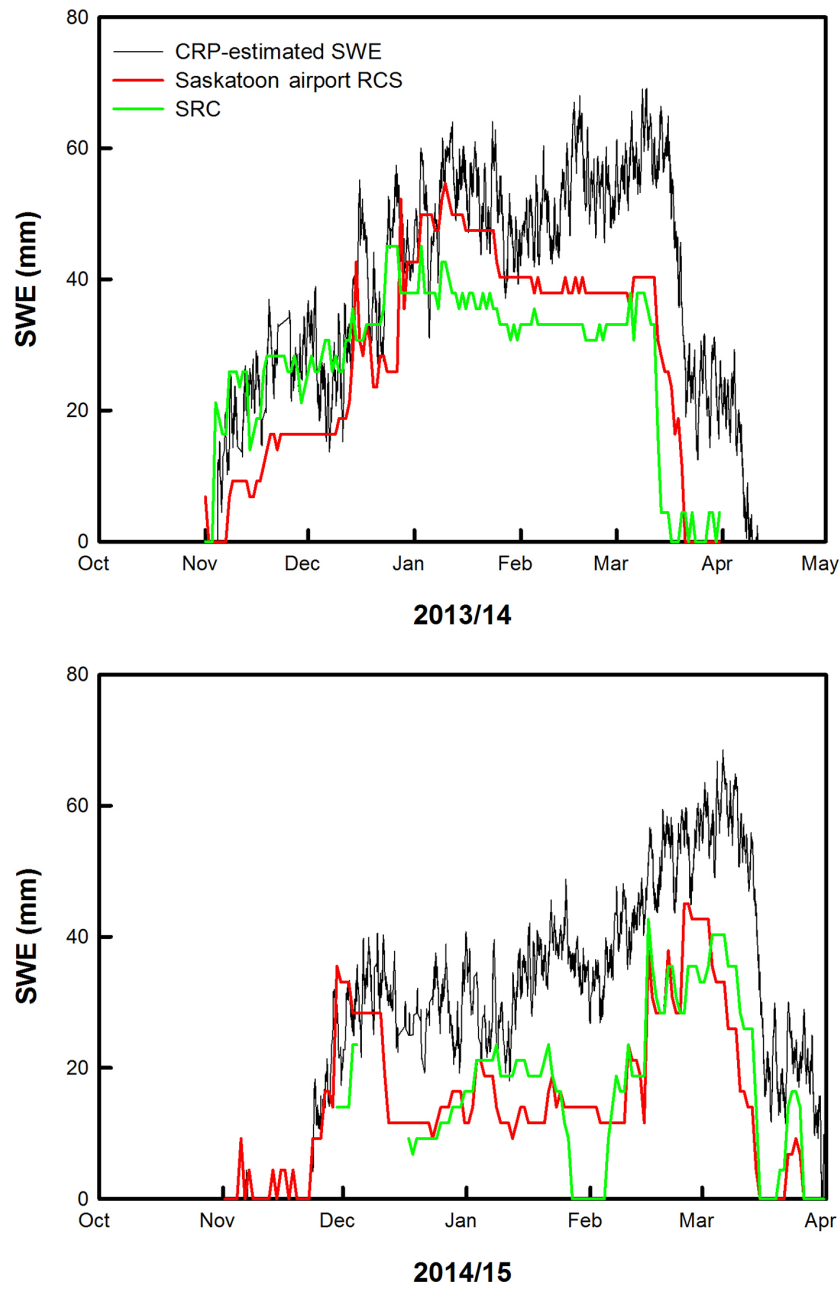

Figure 7. CRP-estimated SWE and SWE estimated from snow depth for 2013/2014 (top) and 2014/2015 (bottom).

our calibration and validation of CRP-estimated SWE. Despite including the $200 \mathrm{~m}$ radial, the calibration provided acceptable estimates of SWE with the CRP when compared to snow surveys, which also included samples from the $200 \mathrm{~m}$ radial. The linear regression and calibration was redone using only the snow samples from the 25 and $75 \mathrm{~m}$ radials, but the regression slope and intercept was similar to the original regression (SWE samples from 25, 75, and $200 \mathrm{~m}$ radials). Furthermore, the RMSE of the CRP-estimated SWE did not improve when using the 25 and $75 \mathrm{~m}$ radial calibration. The characteristics of the study site is most likely the reason why including the $200 \mathrm{~m}$ radial for calibration and assuming a larger footprint $(300 \mathrm{~m})$ provided similar results as the calibration without the samples from the $200 \mathrm{~m}$ radial. The study site is flat and relatively bare of vegetation (short crop stubble evenly throughout field), causing the variability of SWE to be similar throughout the entire site. Using radials closer to the CRP when calibrating for SWE measurements would likely be necessary in other sites where vegetation or 
topography causes SWE distribution to be distinctly heterogeneous: for example, if the CRP were located in a depression where greater amounts of snow accumulated around vs. further away from the probe.

\section{Conclusions}

A simple empirical equation for estimating SWE with the use of a cosmic-ray soil moisture probe was presented. It was found that the relationship between above-ground moderated neutron intensity and manually measured field SWE was well represented by a negative linear function. CRP-estimated SWE corresponded well with snow surveys performed inside the CRP's measurement footprint. SWE estimates based on snow depth measurements at two sites near the study site were also in accordance with the CRP-estimated SWE. Overall, the presented equation performed favourable with regard to providing an estimate of average field SWE at this agricultural study site.

There are several advantages associated with measuring SWE using a CRP. The measurement footprint of the CRP ( $\sim 300 \mathrm{~m}$ radius) is appealing since it provides a measurement scale between that of the point scale (snow tubes, snow pillows) and large scale (remote sensing). The CRP can be installed in remote locations where consistent snow surveys are not possible. It is far less laborious to estimate SWE passively using the CRP than to conduct field-scale snow surveys. Also, the CRP can provide a continuous estimate of SWE throughout the winter season. Furthermore, there are currently numerous CRPs located worldwide, for example the US COSMOS network (Zreda et al., 2012), that currently only collect soil water data but could collect SWE data at no additional cost.

One apparent limitation with using the CRP to estimate SWE arises from the occurrence of considerable snowmelt during the winter months. Significant snowmelt occurred in both of the studied winter seasons and both situations caused the CRP to overestimate SWE. Hydrogen molecules affect moderated neutron intensity, and thus any melted snow is still recognised by the CRP despite not actually representing snow (SWE) in the field. However, it appears that it requires substantial snowpack melt in order for the CRP to overestimate SWE.

Similar to the way the moderated neutron intensity is affected by snowmelt water, the CRP measurement is also influenced by the soil water storage in the top of the soil profile beneath the snowpack being measured. CRPs may overestimate SWE by measuring water in soil just below the snow cover. However, the overestimation may be advantageous in some cases because soil water in the surface soil is largely similar to SWE and controls snowmelt infiltration and surface runoff (Niu and Yang, 2006). Knowing the soil water storage in the upper soil profile is important when applying the presented empirical function at other sites. Differences in soil water storage in the top $10 \mathrm{~cm}$ of the soil profile between the two winter seasons in this study clearly showed the effect that water near the soil surface has on the CRP measurement. Therefore, it is important to have a measurement or estimate of the soil water storage in the upper soil profile before snowfall accumulation occurs. This measurement of soil water storage could be measured by the CRP if installed and calibrated before snowfall or in situ soil moisture probes could be used at the soil surface until freezing. Better understanding the depth to which water within the top of the soil profile affects the CRP reading when a snowpack is present should be looked at in future studies. Other future research should focus on assessing the performance of the empirical relationship at other sites similar to this agricultural study site as well as other forested sites with increased vegetation and snowfall interception.

Acknowledgements. We would like to thank NSERC, COSIA, the University of Saskatchewan, and the China 111 project (B12007). We also would like to acknowledge the Saskatchewan Research Council and Saskatoon Airport RCS for data. We thank the Plant Science department at the University of Saskatchewan for allowing the use of their research field. The NMDB database (www.nmdb.eu), founded under the European Union's FP7 programme (contract no. 213007), is acknowledged for the use of data from the Fort Smith neutron monitor. Eric Neil, Trent Pernitsky, Wei Hu, and Ivanna Faucher are thanked for their help with conducting snow surveys.

Edited by: P. Marsh

\section{References}

Archer, D. and Stewart, D.: The installation and use of a snow pillow to monitor snow water equivalent, Water Environ. J., 9, 221230, 1995.

Desilets, D. and Zreda, M.: Spatial and temporal distribution of secondary cosmic-ray nucleon intensities and applications to in situ cosmogenic dating, Earth Planet. Sci. Lett., 206, 21-42, 2003.

Desilets, D. and Zreda, M.: Footprint diameter for a cosmic-ray soil moisture probe: Theory and Monte Carlo simulations, Water Resour. Res., 49, 3566-3575, 2013.

Desilets, D., Zreda, M., and Ferré, T. P. A.: Nature's neutron probe: Land surface hydrology at an elusive scale with cosmic rays, Water Resour. Res., 46, 1-7, 2010.

Dietz, A. J., Kuenzer, C., Gessner, U., and Dech, S.: Remote sensing of snow - a review of available methods, Int. J. Remote Sens., 33, 4094-4134, 2012.

Fang, X. and Pomeroy, J. W.: Modelling blowing snow redistribution to prairie wetlands, Hydrol. Process., 23, 2557-2569, 2009.

Franz, T. E., Zreda, M., Ferre, T. P. A., Rosolem, R., Zweck, C., Stillman, S., Zeng, X., and Shuttleworth, W. J.: Measurement depth of the cosmic ray soil moisture probe affected by hydrogen from various sources, Water Resour. Res., 48, 1-9, 2012a. 
Franz, T. E., Zreda, M., Rosolem, R., and Ferre, T. P. A.: Field Validation of a Cosmic-Ray Neutron Sensor Using a Distributed Sensor Network, Vadose J., 11, 1-10, 2012 b.

Gardner, W.: Water content, in: Methods of Soil Analysis: Part 1 - Physical and Mineralogical Methods, edited by: Klute, A., Soil Science Society of America, Inc., Madison, USA, 493-544, 1986.

Goodison, B. E.: Accuracy of snow samplers for measuring shallow snowpacks: an update, Proc. 35th Annu. Meet. East. Snow Conf., Hanover, New Hampshire, USA, 36-49, 1978.

Goodison, B. E., Ferguson, H. L., and McKay, G. A.: Measurement and data analysis, edited by: D. M. Gray and D. H. Male, Handbook of Snow: Principles, Processes, Management and Use. Pergamon Press, Toronto, Canada, 191-274, 1981.

Goodison, B. E., Glynn, J. E., Harvey, K. D., and Slater, J. E.: Snow Surveying in Canada: A Perspective, Can. Water Resour. J., 12, 27-42, 1987.

Gray, M. and Landine, P. G.: An energy-budget snowmelt model for the Canadian Prairies, Can. J. Earth Sci., 25, 1292-1303, 1988.

Hobbs, P. V.: Ice physics, Oxford University Press, Great Britain, England, 346-357, 1974.

Kodama, M., Nakai, K., Kawasaki, S., and Wada, M.: An application of cosmic-ray neutron measurements to the determination of the snow-water equivalent, J. Hydrol., 41, 85-92, 1979.

Köhli, M., Schron, M., Zreda, M., Schmidt, U., Dietrich, P., and Zacharias, S.: Footprint characteristics revised for field-scale soil moisture monitoring with cosmic-ray neutrons, J. Hydrol., 6, 119, 2015.

Luojus, K., Pulliainen, J., Takala, M., Derksen, C., Rott, H., Nagler, T., Solberg, R., Wiesmann, A., Metsamaki, S., Malnes, E., and Bojkov, B.: Investigating the feasibility of the globsnow snow water equivalent data for climate research purposes, Geosci. Remote Sens. Symp. (IGARSS), 2010 IEEE Int., 19, 4851-4853, 2010.

Niu, G.-Y. and Yang, Z.-L.: Effects of frozen soil on snowmelt runoff and soil water storage at a continental scale, J. Hydrometeorol., 7, 937-953, 2006.
Paquet, E., Laval, M., Basalaev, L. M., Belov, A., Eroshenko, E., Kartyshov, V., Struminsky, A., and Yanke, V.: An application of cosmic-ray neutron measurements to the determination of the snow-water equivalent, Proc. 30th Int. Cosm. Ray Conf., 1, 761764, 2008.

Pomeroy, J. W. and Gray, D. M.: Snowcover: Accumulation, relocation and management, NHRI Science Report No. 7, 1995.

Pomeroy, J. W. and Goodison, B. E.: Winter and snow, in: The surface climates of Canada, edited by: Bailey, W. G., Oke, T. R., and Rouse, W. R., McGill-Queen's University Press, Montreal, Canada, 68-100, 1997.

Rasmussen, R., Baker, B., Kochendorfer, J., Meyers, T., Landolt, S., Fischer, A. P., Black, J., Thériault, J. M., Kucera, P., Gochis, D., Smith, C., Nitu, R., Hall, M., Ikeda, K., and Gutmann, E.: How Well Are We Measuring Snow: The NOAA/FAA/NCAR Winter Precipitation Test Bed, Bull. Am. Meteorol. Soc., 93, 811-829, 2012.

Rivera Villarreyes, C. A., Baroni, G., and Oswald, S. E.: Integral quantification of seasonal soil moisture changes in farmland by cosmic-ray neutrons, Hydrol. Earth Syst. Sci., 15, 3843-3859, doi:10.5194/hess-15-3843-2011, 2011.

Rosolem, R., Shuttleworth, W. J., Zreda, M., Franz, T. E., Zeng, X., and Kurc, S. A.: The effect of atmospheric water vapor on neutron count in the cosmic-ray soil moisture observing system, J. Hydrometeorol., 14, 1659-167, 2013.

Shook, K. and Gray, D. M.: Determining the snow water equivalent of shallow prairie snowcovers, Proceedings of the 51st Eastern Snow Conference, Dearborn, Michigan, USA, 89-95, 1994.

Shook, K. and Gray, D.: Small-scale spatial structure of shallow snowcovers, Hydrol. Process., 10, 1283-1292, 1996.

Zreda, M., Desilets, D., Ferré, T. P. A., and Scott, R. L.: Measuring soil moisture content non-invasively at intermediate spatial scale using cosmic-ray neutrons, Geophys. Res. Lett., 35, 1-5, 2008.

Zreda, M., Shuttleworth, W. J., Zeng, X., Zweck, C., Desilets, D., Franz, T., and Rosolem, R.: COSMOS: the COsmic-ray Soil Moisture Observing System, Hydrol. Earth Syst. Sci., 16, 40794099, doi:10.5194/hess-16-4079-2012, 2012. 